\title{
Microwave Sintering of Zn-Nb Doped Barium Hexaferrite Synthesized via Sol-Gel Method
}

\author{
Samikannu Kanagesan 1*, Mansor Hashim1, Sinnappan Jesurani², \\ Thirunavukarasu Kalaivani ${ }^{3}$, Ismayadi Ismail ${ }^{1}$ \\ ${ }^{1}$ Materials Synthesis and Characterization Laboratory (MSCL), Institute of Advanced Technology (ITMA), \\ Universiti Putra Malaysia, Serdang, Malaysia \\ ${ }^{2}$ Department of Physics, Jeyaraj Annapackium College for Women, Periyakulam, India \\ ${ }^{3}$ Center for Material Science and Nano Devices, Department of Physics, SRM University, Kattankulathur, India \\ Email: ${ }^{*}$ kanagu1980@gmail.com
}

Received 5 November 2013; revised 21 December 2013; accepted 18 January 2014

Copyright (C) 2014 by authors and Scientific Research Publishing Inc.

This work is licensed under the Creative Commons Attribution International License (CC BY).

http://creativecommons.org/licenses/by/4.0/

(c) (i) Open Access

\begin{abstract}
A series of polycrystalline M-type hexagonal ferrites with the formula $\mathrm{BaFe}_{12-2 \mathrm{x}} \mathrm{Zn}_{\mathrm{x}} \mathrm{Nb}_{\mathrm{x}} \mathrm{O}_{19}(\mathrm{x}=0.2$, $0.4,0.6,0.8 \mathrm{~mol} \%$ ) have been synthesized by the sol-gel method. The composition and microstructure govern the magnetic properties of ferrites. The XRD analysis shows the formation of pure magneto plumbite phase without any other impurity phases. The Zn-Nb substitutions in barium hexaferrite have been confirmed through magnetic measurements. The results show that the magnetic properties are closely related to the distributions of $\mathrm{Zn}-\mathrm{Nb}$ ions on the five crystallographic sites. The saturation magnetization and coercivity increase with increasing $\mathrm{Zn}$-Nb concentration.
\end{abstract}

\section{Keywords}

Ceramics; Magnetic Materials; Surface Properties; Magnetic Properties

\section{Introduction}

Barium hexaferrite $(\mathrm{BaF})$ is well established for the use as a permanent magnetic material [1]. BaF exhibits a fairly large magneto crystalline anisotropy and high Curie temperature and has in addition, a relatively large saturation magnetization, chemical stability and corrosion resistivity [2]. The main reason for its great success is its low cost and its moderate magnetic properties. BaF ferrites exhibit suitable properties in a wide range of industrial applications. The doped hexaferrites show that the saturation magnetization decreases slightly and coercivity decreases dramatically with increasing doping content. It is suggested that a combination of dopants can

*Corresponding author. 
be used to control or to reduce the coercivities with only a small change of their saturation magnetizations [3]-[5]. Furthermore, the substitutions of Fe ions by isovalent cations can be generally investigated. Many attempts have been made to improve its magnetic properties by divalent-tetravalent and trivalent cationic substitution for $\mathrm{Fe}^{3+}$ ion situated at the five different crystallographic sites. The magnetic properties of the substituted hexaferrites are strongly depending on electronic configuration of the substituted cations as well as on their site preference. Several combinations of substituents such as Zn-Zr, Co-Ti, Zn-Ti, Ni-Ti and others have been investigated and reported [6]-[9]. Zn-Nb substituted SrF is a new kind of very promising particulate material for magnetic recording [10].

Because it is a non-contact sintering technique, the heat is transferred to the product via electromagnetic waves and large amounts of heat can be transferred to materials interior, minimizing the effects of differential heating sintering [11]. Recently sintering of ceramics using microwave energy received much attention due to its advantages over conventional sintering techniques such as lower sintering temperature, reduced sintering time, including rapid volumetric heating, high production rates and low energy consumption and capabilities of producing unique microstructure that could not otherwise possible to achieve by conventional methods [12]-[14]. This paper gives the structural and magnetic parameters of microwave sintered barium hexaferrites having substituted pairs of $\mathrm{Zn}-\mathrm{Nb}$ ions, prepared by sol-gel method.

\section{Experimental Techniques}

$\mathrm{Ba}\left(\mathrm{NO}_{3}\right)_{2}(99.5 \%)$, Fe $\left(\mathrm{NO}_{3}\right)_{3} \cdot 9 \mathrm{H}_{2} \mathrm{O}(99.9 \%), \mathrm{Zn}\left(\mathrm{NO}_{3}\right)_{2} \cdot 6 \mathrm{H}_{2} \mathrm{O}, \mathrm{NbCl}_{5}$ and D-Fructose were used as raw materials. The chemicals were weighed and mixed according to determined proportion. Nitrates and D-Fructose solutions were mixed with continuous stirring heated up to $80^{\circ} \mathrm{C}$ to get a sticky liquid gel. Then the mixture was heated at $130^{\circ} \mathrm{C}$ in the hot air oven for 2 days, which turned into a dried precursor. Powders of the dried precursor were calcined and pellets were made. These pellets were microwave sintered at $1150^{\circ} \mathrm{C}$ for 10 minutes. Diffraction patterns of the samples were recorded by X-ray diffract meter (PANalytical X'pert pro). The morphological characteristics of the samples were investigated by Field emission scanning electron microscopy (FE-SEM). The specific saturation magnetization and coercivity of the substituted $\mathrm{BaFe}_{12} \mathrm{O}_{19}$ were measured by means of Lakeshore 7304 Vibrational Sample Magnetometer (VSM) at a maximum applied field of $15 \mathrm{kOe}$ at room temperature.

\section{Results and Discussion}

\subsection{Structural Analysis}

XRD patterns of Zn-Nb substituted Ba hexaferrite ceramics is as shown in Figure 1. The observed peaks exactly match with the standard pattern for M-type hexaferrite (ICSD-39-1433). The substituted samples can completely be dissolved in the magneto plumbite lattice and no intermediate phases in the hexagonal plane of magneto plumbite structure are observed. Variation of lattice parameters (a, c) as a function of $\mathrm{Zn}-\mathrm{Nb}$ content is shown in Table 1. It is evident that the value of "a" remains almost constant, while that of c slightly increases with increasing the dopant contents. It indicates that the change of the main axis (c-axis) is larger than that of a-axis for the substitution with $\mathrm{Zn}-\mathrm{Nb}$ ion. The observed variation depends on the difference in the ionic radii of the metal ions $\mathrm{Zn}=0.74 \AA, \mathrm{Nb}=0.69 \AA$ compare to $\mathrm{Fe}=0.645 \AA$.

\subsection{Surface Morphological Analysis}

Figure 2 shown a FE-SEM micrograph of the surface with the composition $\mathrm{BaFe}_{12-2 \mathrm{x}} \mathrm{Zn}_{\mathrm{x}} \mathrm{Nb}_{\mathrm{x}} \mathrm{O}_{19}$ at 0.2 (Figure 2(a)) and 0.8 (Figure 2(b)) sintered at $1150^{\circ} \mathrm{C}$ for 10 minutes. The grain size increases with increasing substitution 0.2 to 0.8 is due to the ionic radius of $\mathrm{Zn}$ and $\mathrm{Nb}$ is high compare to Fe. This suggests that $\mathrm{Zn}-\mathrm{Nb}$ substitutions encourage the grain growth as confirmed by the HR-SEM micrographs [15]. Energy dispersive $\mathrm{X}$-ray (EDX) analysis of $\mathrm{BaFe}_{12-\mathrm{x}} \mathrm{Zn}_{\mathrm{x}} \mathrm{Nb}_{\mathrm{x}} \mathrm{O}_{19}(\mathrm{x}=0.8 \mathrm{~mol} \%)$ sample shows the evidence for the presence of $\mathrm{Zn}-\mathrm{Nb}$ in Figure 2(b) (inset).

\subsection{Magnetic Analysis}

Figure 3 shows an increase in the values of $\mathrm{M}_{\mathrm{s}}$ with the substitution of $\mathrm{Zn}-\mathrm{Nb}$ ions up to $\mathrm{x}=0.8 \mathrm{~mol} \%$. At the 


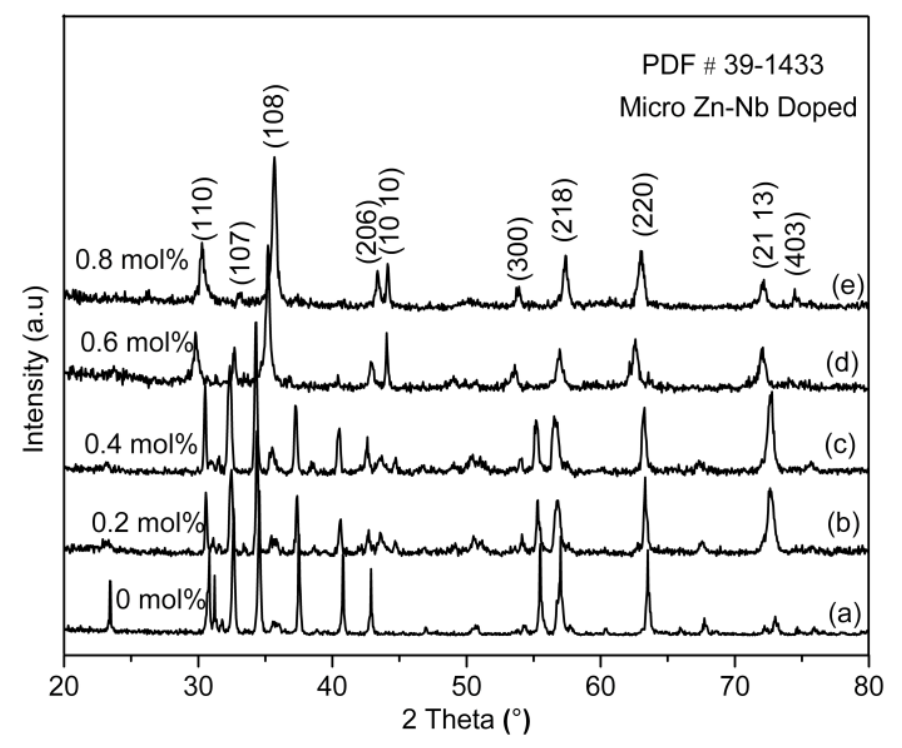

Figure 1. XRD pattern of microwave sintered $\mathrm{BaFe}_{12-2 \mathrm{x}} \mathrm{Zn}_{\mathrm{x}} \mathrm{Nb}_{\mathrm{x}} \mathrm{O}_{19}$ with different doping concentration.

Table 1. Variation of lattice parameters with Zn-Nb substitution.

\begin{tabular}{ccccc}
\hline S. No. & Hexaferrites $\left(1150^{\circ} \mathrm{C}\right)$ & Lattice parameters $\mathrm{a}=\mathrm{b}$ & Lattice parameter c & Lattice system \\
\hline 1 & $\mathrm{BaFe}_{11.6} \mathrm{Zn}_{0.2} \mathrm{Nb}_{0.2} \mathrm{O}_{19}$ & 5.89 & 23.19 & \\
2 & $\mathrm{BaFe}_{11.2} \mathrm{Zn}_{0.4} \mathrm{Nb}_{0.4} \mathrm{O}_{19}$ & 5.92 & 23.20 & Hexagonal \\
3 & $\mathrm{BaFe}_{10.8} \mathrm{Zn}_{0.6} \mathrm{Nb}_{0.6} \mathrm{O}_{19}$ & 5.89 & 23.21 & \\
4 & $\mathrm{BaFe}_{10.4} \mathrm{Zn}_{0.8} \mathrm{Nb}_{0.8} \mathrm{O}_{19}$ & 5.86 & 23.07 & \\
\hline
\end{tabular}

same time $\mathrm{H}_{\mathrm{c}}$ slightly decreases and then increases on further substitution. Variation of magnetic properties, explained with the help of previous published research reports. This is likely due to the site occupancy of the doped metal ions at different lattice sites. Substitution of the $\mathrm{Fe}^{3+}$ ions in the spin-up states (12k, 2a, 2b) appears to cause reduction in magnetization, while the substitution in the spin-down $(4 \mathrm{f} 1,4 \mathrm{f} 2)$ states may lead to an increase in the net magnetization [16].

It had been reported that $\mathrm{Zn}^{2+}$ ions have a strong preference of substituting $\mathrm{Fe}^{3+}$ ions in $4 \mathrm{f} 1$ tetrahedral down spin sites and essentially yield an increase of saturation magnetization $\mathrm{M}_{\mathrm{s}}$ [17] [18], while $\mathrm{Nb}^{4+}$ ions may enter 4f2 (spin down) and $12 \mathrm{k}$ (spin up) octahedral sites [10]. Due to collinearity of strong magnetic structure depending on $12 \mathrm{k}$ sites, the diamagnetic $\mathrm{Nb}^{4+}$ ions in $12 \mathrm{k}$ sites will lead to the collinearity of tetragonal-octahedral super exchange interactions being progressively broken as substitution increases [19]; also, the localization of $\mathrm{Nb}^{4+}$ ions in $4 \mathrm{f} 2$ sites will lead to local spin canting [20]. The coercivity of the samples decreases slightly and then increases with an increase in substitution level. The $\mathrm{H}_{\mathrm{c}}$ variation is mainly influenced by the effective anisotropy constant K1 dependent on the crystalline and the shape anisotropy [21]. Another reason for various in coercivity is extrinsic effect which causes variation in grain size with substitution [22].

\section{Conclusion}

The present investigation effects of Zn-Nb substitution on Fe crystallographic sites on structural and magnetic properties of barium hexaferrite are reported. Substitution of $\mathrm{Zn}-\mathrm{Nb}$ in barium hexaferrite was indirectly confirmed from the magnetic measurements. It is found that the substitution of $\mathrm{Zn}$ (II)-Nb (IV) did not change the structure of the XRD pattern. High levels of substitutions expectedly change the magnetic properties of the ferrite. The addition of $\mathrm{Zn}-\mathrm{Nb}$ favored grain growth and smaller grain size, which was proportional to the amount of dopant. From the results, it is concluded that microwave heat treatment is found to be simple, fast, capable of 

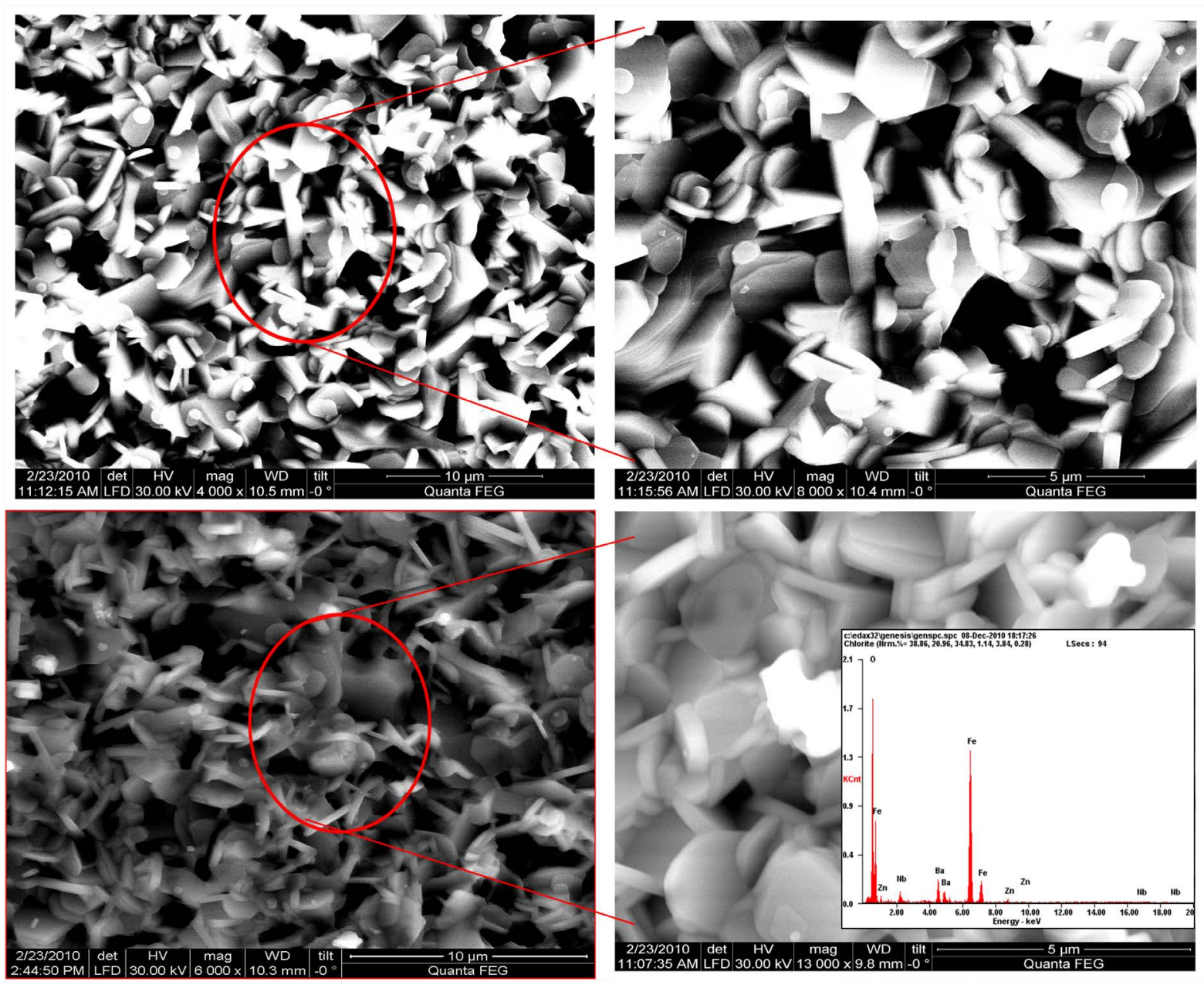

Figure 2. (a), (b) HR-SEM image of $\mathrm{BaFe}_{12-\mathrm{x}} \mathrm{Zn}_{\mathrm{x}} \mathrm{Nb}_{\mathrm{x}} \mathrm{O}_{19}(\mathrm{x}=0.2,0.8 \mathrm{~mol} \%)$ microwave sintered at $1150^{\circ} \mathrm{C}$ for 10 minutes.

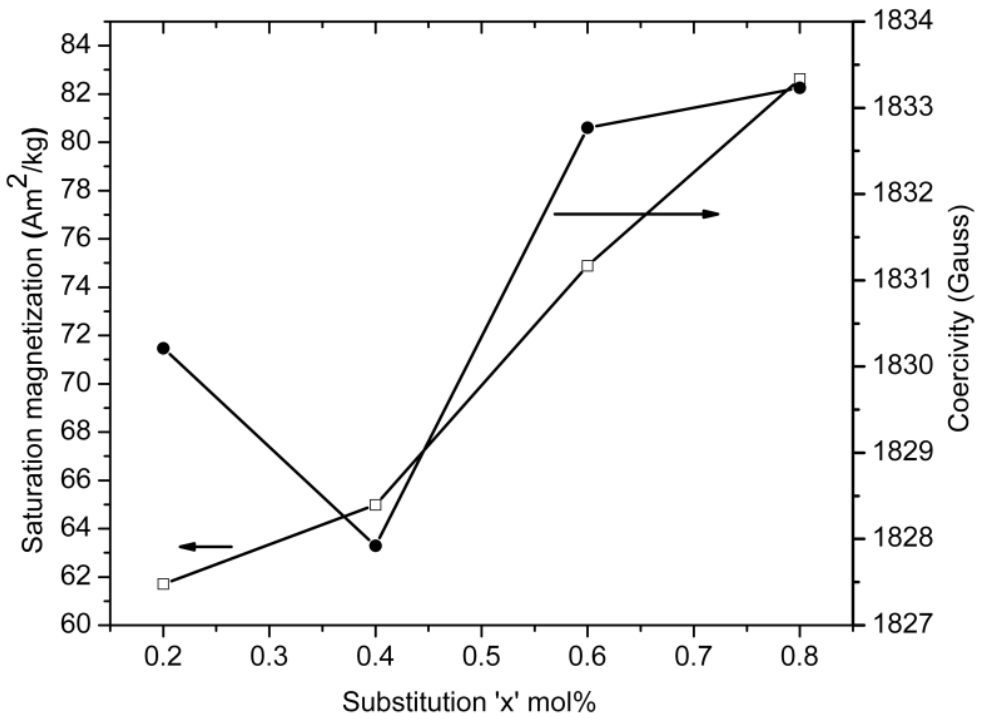

Figure 3. The specific saturation magnetization $\left(\mathrm{M}_{\mathrm{s}}\right)$ and the coercivity $\left(\mathrm{H}_{\mathrm{c}}\right)$ of microwave sintered $\mathrm{BaFe}_{12-\mathrm{x}} \mathrm{Zn}_{\mathrm{x}} \mathrm{Nb}_{\mathrm{x}} \mathrm{O}_{19}$ as a function of substitution content " $\mathrm{x}$ " mol\% at room temperature. 
reducing the processing time and the grain size.

\section{Acknowledgements}

We would like to thank SRM UNIVERSITY for providing the Nanotechnology center Facilities and ITMA, UNIVERSITI PUTRA MALAYSIA for the pre-submission final editing of this paper.

\section{References}

[1] Kojima, H. (1982) Fundamental Properties of Hexagonal Ferrites. In: Wohlfahrt, E.P., Ed., Ferromagnetic Materials, North-Holland, Amsterdam.

[2] Liu, X., Wang, J., Gan, L.M., Ng, S.C. and Ding, J. (1998) An Ultrafine Barium Ferrite Powder of High Coercivity from Water-in-Oil Microemulsion. Journal of Magnetism and Magnetic Materials, 184, 344-354. http://dx.doi.org/10.1016/S0304-8853(97)01141-4

[3] An, S.Y., Shim, I.B. and Kim, C.S. (2002) Mossbauer and Magnetic Properties of Co-Ti Substituted Barium Hexaferrite Nanoparticles. Journal of Applied Physics, 91, 8465-8468. http://dx.doi.org/10.1063/1.1452203

[4] Zhou, X.Z., Morrish, A.H., Yang, Z. and Zeng, H.-X. (1994) Co-Sn Substituted Barium Ferrite Particles. Journal of Applied Physics, 75, 5556-5558. http://dx.doi.org/10.1063/1.355687

[5] Han, D.H., Yang, Z., Zeng, H.X., Zhou, X.Z. and Morrish, A.H. (1994) Cation Site Preference and Magnetic Properties of Co-Sn-Substituted Ba Ferrite Particles. Journal of Magnetism and Magnetic Materials, 137, 191-196. http://dx.doi.org/10.1016/0304-8853(94)90205-4

[6] Li, Z.W., Ong, C.K., Yang, Z., Zhou, X.Z., Zhao, J.H. and Morrish, A.H. (2000) Site Preference and Magnetic Properties of Perpendicular Recording Material, $\mathrm{BaFe}_{12-\mathrm{x}}, \mathrm{Zn}_{\mathrm{x} / 2} \mathrm{Zr}_{\mathrm{x} / 2} \mathrm{O}_{19}$ Nanoparticles. Physical Review B, 62, 6530-6537. http://dx.doi.org/10.1103/PhysRevB.62.6530

[7] Mendoza-Suarez, G., Corral-Huacuz, J.C., Contreras-Garcia, M.E. and Juarez-Medina, H. (2001) Magnetic Properties of $\mathrm{BaFe}_{11.6-2 \mathrm{x}} \mathrm{Co}_{\mathrm{x}} \mathrm{Ti}_{\mathrm{x}} \mathrm{O}_{19}$ Particles Produced by Sol-Gel and Spray-Drying. Journal of Magnetism and Magnetic Materials, 234, 73-79. http://dx.doi.org/10.1016/S0304-8853(01)00286-4

[8] Wartewig, P., Krause, M.K., Esquinazi, P., Rosler, S. and Sonntag, R. (1999) Magnetic Properties of Zn- and Ti-Substituted Barium Hexaferrite. Journal of Magnetism and Magnetic Materials, 192, 83-99. http://dx.doi.org/10.1016/S0304-8853(98)00382-5

[9] Turilli, G., Licci, F., Paoluzi, A. and Besagni, T. (1998) NiTi Substituted Hexaferrites for Magnetic Recording. IEEE Transactions on Magnetics, 24, 2146-2149. http://dx.doi.org/10.1109/20.3418

[10] Fang, Q.Q., Bao, H.W., Fang, D.M., Wang, J.Z. and Li, X.G. (2004) The Effect of Zn-Nb Substitution on Magnetic Properties of Strontium Hexaferrite Nanoparticles. Journal of Magnetism and Magnetic Materials, 278, 122-126. http://dx.doi.org/10.1016/j.jmmm.2003.12.328

[11] Menezes, R.R. and Akiminami, R.H.G. (2008) Microwave Sintering of Alumina-Zirconia, Nanocomposites. Journal of Materials Processing Technology, 203, 513-519. http://dx.doi.org/10.1016/j.jmatprotec.2007.10.057

[12] Fang, Y., Roy, R., Agrawal, D.K. and Roy, D.M. (1996) Transparent Mullite Ceramics from Diphasic Aerogels by Microwave and Conventional Processings. Materials Letters, 28, 11-15. http://dx.doi.org/10.1016/0167-577X(96)00028-6

[13] Ravi, B.G., Praveent, V. and Panneer, A. (1998) Microwave-Assisted Preparation and Sintering of Mullite-Zirconia Composites from Metal Organics. Materials Research Bulletin, 33, 1527-1536. http://dx.doi.org/10.1016/S0025-5408(98)00135-4

[14] Piluso, P., Gaillard, L. and Lequeux, N. (1996) Mullitization and Densification of $\left(3 \mathrm{Al}_{2} \mathrm{O}_{3}+2 \mathrm{SiO}_{2}\right)$ Powder Compacts by Microwave Sintering. Journal of the European Ceramic Society, 16, 121-125. http://dx.doi.org/10.1016/0955-2219(95)00134-4

[15] Vijayalaksmi, A. and Gajbhiye, N.S. (1998) Magnetic Properties of Single Domain $\mathrm{SrFe}_{12} \mathrm{O}_{19}$ Fine Particles Synthesized by Citrate Precursor Technique. Journal of Applied Physics, 83, 400-407. http://dx.doi.org/10.1063/1.366654

[16] Litsardakis, G., Manolakis, I., Stergiou, A.C., Serletis, C. and Efthimiadis, K.G. (2008) New Dy-Substituted Ba Hexaferrites with Enhanced Coercivity. IEEE Transactions on Magnetics, 44, 4222-4224. http://dx.doi.org/10.1109/TMAG.2008.2001541

[17] Kubo, O. and Ogawa, E. (1994) Barium Ferrite Particles for High Density Magnetic Recording. Journal of Magnetism and Magnetic Materials, 134, 376-381. http://dx.doi.org/10.1016/0304-8853(94)00147-2

[18] Bai, J., Liu, X., Xie, T., Wei, F. and Yang, Z. (2000) The Effects of La-Zn Substitution on the Magnetic Properties of Sr-Magnetoplumbite Ferrite Nano-Particles. Materials Science and Engineering: B, 68, 182-185. 
http://dx.doi.org/10.1016/S0921-5107(99)00593-0

[19] Kubo, O. and Ogawa, E. (1991) Cation Distribution and Intrinsic Magnetic Properties of Co-Ti-Doped M-Type Barium Ferrite. Journal of Applied Physics, 70, 1614-1623.

[20] Parker, R.J. (1980) Ferrite. Proceedings of the ICF-3, 375.

[21] Lisjak, D. and Drofenik, M. (2004) Synthesis and Characterisation of A-Sn-Substituted (A=Zn,Ni,Co) BaM-Hexaferrite Powders and Ceramics. Journal of the European Ceramic Society, 24, 1841-1845. http://dx.doi.org/10.1016/S0955-2219(03)00445-X

[22] Singh, C., Bindra-Narang, S., Hudiara, I.S. and Bai, Y. (2008) The Effect of Co and Zr Substitution on dc Magnetic Properties of Ba-Sr Ferrite. Journal of Alloys and Compounds, 464, 429-433.

http://dx.doi.org/10.1016/j.jallcom.2007.10.009 